\title{
Estudo botanico e chimico da catuaba (Erythroxylaceae Catuaba do Norte)
}

\author{
Arthur José da Silva
}

PARTE III

Estudo chimico da catuaba

\section{Trabalho do Laboratório Municipal da Bahia}

L'etude des végétaus au point de vue chimic, semble n'avoir attiré jusqu'á present qu'un nombre três restraint de travailleurs. Cependant comme l'analyse immediate dês plantes se rattache d'une maniére intime á la botanique, á la matiére médicale et á la thérapeutique, elle meriterait d'étre étudiée avec plus de soin qu'elle ne l'a été présentement.

\section{CAPITULO I - Pesquisa de alcaloides}

Fizemos o estudo chimico da catuaba no Laboratorio Municipal, sob a direcção do illustre mestre Sr. Dr. Alfredo de Andrade, a cuja competencia muito devemos para a completa realisação desta parte do nosso trabalho. Antes de seguirmos o plano doptado por Dragendorff para a analyse chimica dos vegetaes, procuramos por um processo novo e fácil, ver se as virtudes da nossa planta eram devidas a algum alcalóide existente em sua casca. O processo que nos foi aconselhado pelo Sr. Dr. Alfredo de Andrade, é o de Gordim e Prescott para extracção de alcalóides, e que aqui passamos a descrever:

Collocamos em um vaso apropriado 40 grammas de cascas de catuaba reduzidas a pó, e com ellas fizemos uma pasta com a seguinte mistura:

$\begin{array}{lc}\text { Ammoniaco } & 5 \text { volumes } \\ \text { Alcool a } 90^{\circ} & 5, \\ \text { Cholorotmio } & 10, \\ \text { Ether } & 20,\end{array}$

A pasta foi depois tratada por mais 5 vezes o seu volume do liquido precedente, e collocada em um frasco que em seguida foi hermeticamente arrolhado, sendo agitado freqüentemente. No fim de 25 horas foi a mistura exposta ao ar com o fim de evaporar o liquido e de libertal-a de todo o gaz ammoniacal. O residuo tomou uma cór bruna azulada devido á accção do ammoniaco sob a substancia corante do pó.

Depois desta evaporação foi o pó collocado em uma cápsula de porcellana e na platina da machina pneumática, em cima de acido sulfúrico, durante alguns dias. Aqui o processo soffreu uma modificação vantajosa. $\mathrm{O}$ pó foi dividido em duas partes. Uma dellas misturada com 4 vezes o seu peso de chlorureto de sódio foi posta em um extractor de Soxhlet com refrigerante ascendente de Allinh, para ser exgottada pelo chloroformio a quente em banho de vapor.

Este interessantíssimo dispositivo que veio modificar o processo, tem a vantagem de lixiviar a substancia deslocando completamente o seu principio activo, em poucas horas, sem perda do liquido, que evaporado num ballão condensa-se no refrigerante, atravessa o extractor repassando a substancia indefinidamente.

O liquido obtido por esse processo foi tratado pela água acidulada com o acido sulfúrico, agitado diversas vezes e posto a repousar. Decantada a parte aquosa e feitas com ella as reaccoes para a pesquisa de alcalóides, obtivemos resultados negativos, ficando assim demonstrado não existir no extracto essa base vegetal.

Como o alcaloide poderia se ter decomposto na temperatura de $66^{\circ}$, de ebulição de chloroformio, a outra porção do pó foi exgottada a frio, durante alguns dias. Depois de filtrado o extracto foi tratado pela solução acida, sendo agitada muitas vezes. Separada a parte aquosa com ella fizemos em pequenos vidros de relogios as seguintes reacções: Pelo iodureto de potassio iodurado, não houve precipitado algum; pelo reactivo de Mayer, também não obtivemos pre- cipitado.

Para mais segurança o chloroformio foi posto a evaporação na temperatura normal, em vidros de relogio. $\mathrm{O}$ residuo foi ainda tratado pela solução acida, agitado frequentemente, e procurando, por meio das reacções conhecidas, descobrir traços de alcaloides, não obtivemos resultados positivos.

Com esses resultados ficou verificado o primeiro, e mais que demostrado não serem as virtudes da catuaba devidas a um alcaloide existente em sua casca, como suppunhamos. O processo empregado é um dos mais modernos e faceis e tem a vantagem de por uma única operação, substitutiva de todos os diversos methodos de extracção de alcaloides buscar com segurança o principio activo por um liquido que se compõe de todos os solventes delles.

CAPITUlO II - Pesquisas da humidade, cinzas e substancias soluveis nos differentes extractos feitos com casca de catuaba.

Eis a analyse chimica que apressadamente conseguimos fazer para o nosso trabalho, deixando 
de pesquisar ainda algumas substancias por se haver terminado o praso para sua apresentação á Faculdade de Medicina; é mais qualitativa que quantitativa, a analyse quantitativa dos vegetaes não tendo tanta importancia quanto a qualitativa, variando aquella com a epoca, a idade, e a localidade em que se acha o vegetal.

Como já tivemos occasião de dizer seguimos o processo de Dragendorff, preparando os extractos sempre com a mesma quantidade de pó, 50 grammas, a qual foi successivamente tratada pelos diversos dissolventes em prasos necessarios para que a substancia ficasse completamente exgottada.

O modo de exprimir os resultados é o geralmente adoptado pelo Laboratorio Municipal, nos trabalhos deste genero; foi elle utilisado em 1899 pelo Sr. Dr. Rigueira da Costa, que alli fez suas investigações, em sua these inaugural, e vimos identica marcha, seguida recentemente pelo Dr. Saget em sua these apresentada á Faculdade de Lyon sobre o Rumex crispus.

\section{ANALYSE QUANTITATIVA}

A - Humidade 11,110

B - Substancias soluveis no ether de petroleo...... 1,036

$\mathrm{C}$ - Substancias soluveis no ether a $66^{\circ} \quad$............. 1,240

D - Substancias soluveis no alcool absoluto ....... 11,960

E - Substancias soluveis n'agua destillada ......... 4,600

F - Substancias soluveis na soda caustica diluida.. 1,340

$\mathrm{G}$ - Substancias soluveis no acido chlorhydrico

diluido

$\mathrm{H}$ - Substancias que escaparam á acção

dos dissolventes.....

I - Substancias mineraes fixas.

100,000

\section{ANALYSE QUALITATIVA}

A - A casca do vegetal que serviu para a determinação da humidade foi seccada ao sol. Depois de pulverisada collocamos 10 grammas numa capsula de platina, tarada em balança de precisão, sob a campanula de uma machina pneumatica, em cima de acido sulfurico, durante trinta dias, fazendo-se o vasio na machina diariamente. Pesada a capsula com o pó tivemos a humidade por differença.

Esta humidade não representa, pois, a relação entre a quantidade dagua e o total das substancias solidas, tal como ella existe normalmente na planta, mas a humidade da casca que soffreu um deseccamento prévio para ser reduzida a pó.

$\mathrm{B}-\mathrm{O}$ ether de petroleo deu um extracto limpido, amarello ambar, com um cheiro ligeiramente aromatico. Depois de filtrado e evaporado todo o ether, o extracto deixou um residuo constituido por um oleo essencial, citrino, de cheiro aromatico, suave e agradavel, tornandose muito activo com a addição de um pouco de potassa; sabor ligeiramente acre e amargo, produzindo por seu contacto com a lingua uma impressão semelhante a da essencia de hortelã-pimenta. Esse oleo é soluvel em duas partes de ether a $66^{\circ}$, muito soluvel em seis volumes de alcool a $90^{\circ}$, insoluvel no ammoniaco, com o qual forma uma emulsão. Pelo acido azotico nitroso dá uma coloração vermelha escura que passa a bruna, e no fim de uma hora a verde folha morta. Saponifica-se com facilidade em uma solução alcoolica de potassa.

$\mathrm{C}-\mathrm{O}$ extracto preparado com o ether a $66^{\circ}$ apresentou uma côr amarellada. O residuo da evaporação deste extracto deu uma resina amarella queimado, filamentosa, com ligeiras fluorescencias verdes e cheiro perfumoso. O chloroformio a dissolveu em parte, deixando pela evaporação uma substancia amarella esverdinhada, pegasoja, lembrando por suas propriedades a terebenthina.

A parte insoluvel no chloroformio tem a côr amarella escura e é soluvel no alcool. A resina é soluvel em parte no sulfureto de carbono, soluvel no alcool absoluto, no alcool a $90^{\circ}$ e quase insoluvel no alcool a $60^{\circ}$. Tratada pela potassa alcoolica dissolveu-se bem; é, portanto, uma resina acida.

A solução potassica da resina tratada pelo acido chlorhydrico depoz grumos ligeiramente amarellados, provando assim não se tratar de uma resina indifferente. Além da resina encontra-se no extracto traços de uma materia corante vermelha, que tomou um matiz muito vivo com a juncção da potassa.

D - O alcool absoluto depois de exgottar a substancia nos deu um extracto vermelho vivo, visto atravez da luz, e de sabor fortemente amargo. Destillado o extracto para concentrar, foi collocado em uma capsula de vidro e posto a evaporar o resto do alcool na temperatura ambiente, sendo em seguida levado ao vacuo, em cima de acido sulfurico para perder a humidade.

Depois de evaporado todo o alcool e bem secca a capsula, ficou uma substancia de côr escura, com a consistencia de extracto molle, cheiro caracteristico e gosto amargo, rodeada por uma zona mais clara, secca, friavel, quebrando-se facilmente ao ser tocada com a ponta dos dedos.

Aaguadestillada dissolveuparte dessa substancia, deixando no fundo da capsula uma outra escura, que tomou a consistencia de uma resina, adherente ao fundo da capsula. Filtrado o soluto aquoso tomamos delle uma porção, e tratamol-a por uma solução de gelatina e pelo perchlorureto de ferro, obtendo um precipitado verde côr de folha morta que veio denunciar a existencia de tanino que foi depois isolado.

Uma outra porção da solução aquosa foi tratada pelo acetato de chumbo, formando-se um deposito côr de tijolo claro que se decantou em poucos minutos. Defecada e filtrada esta porção foi tratada pelo sulfato de sodio para eliminar o excesso de chumbo e pelo licor de Fehling. Este ultimo reactivo não foi reduzido immediatamente, entretanto no fim de algumas horas appareceu um 
precipitado vermelho de oxydulo de cobre, demonstrando a existencia de uma glycose soluvel no alcool.

Para verificar se a reducção do licor de Fehling era realmente devido a uma glycose e não a substancias reductoras outras, fizemos a reacção da phenylhydrasina, conseguindo os cristaes carcteristicos de uma ozasoma. Ainda nesta solução que tinha sabor ligeiramente amargo pesquisamos alcaloides sem resultados positivos.

O deposito formado pelo acetato de chumbo, côr de tijollo claro, collocado em um frasco e tratado pela agua destillada, depois de repousar, se dividiu em duas partes: uma inferior, especie de magma constituida pelo tanino, e outra superior em suspensão n'agua deixando ver por seu vermelho escuro a existencia de uma materia corante, que em contacto com o oxygeneo do ar se transformou em vermelho vivo. Alem desta ainda notamos uma outra substancia corante amarella que tingiu fortemente os fltros por varias vezes.

O residuo que destillada rejeitou, foi tratado pela agua ammoniacal, dissolvendo-se completamente nesse vehiculo. Collocada esta solução ammoniacal em uma capsula de platina e evaporada a banho de vapor, abandonou um deposito, côr de borra de vinho, lustroso, secco, com os caracteres dos phlobaphenos, productos da decomposição do tanino.

Retomamos uma outra porção de extracto alcoolico e depois de seccal-o em banho de vapor, notamos que o seu sabor amargo havia desapparecido, sendo substituido por um adocicado um pouco acido, semelhando o da polpa de tamarindos. Este facto nos fez presumir a existencia de uma glycoside que passamos a pesquisar.

Preparada uma nova quantidade de extracto alcoolico foi este tratado pelo acetato de chumbo para precipitar o tanino, pelo oxydo de chumbo para neutralisar o acido e pelo carbonato de sodio para arrastar alguns traços de chumbo. Depois de filtrado juntamos chloroformio que decantado foi collocado em vidros de relogio para evaporar no vasio, sob a campanula de uma machina pneumatica. O residuo é constituido por uma substancia amorpha, esbranquiçada, fortemente amarga, com os caracteres de uma glycoside muito appproximada do tanino. Um tanino glycoside como considera Behal.

É pouco soluvel no ether de petroleo, quase insoluvel no ether a $66^{\circ}$, mais soluvel n'agua, completamente soluvel no alcool absoluto e no chloroformio. Esta glycoside com facilidade se desdobra, sob a influencia dos acidos, sobretudo do calor e da luz, em glycose e em uma outra substancia resinosa, amarellada, de aspecto vitreo, formando um inducto adherente ao vaso em que se acha. Cremos que esta glycoside ainda não foi por ninguem estudada, por essa razão the propomos o nome de catuabina, reservando o de catuagenina para a substancia resinosa em que ella se transforma.

Esta nomenclatura é derivada do nome vulgar, indigena que tem o vegetal; o modo de formação obedeceu, por analogia, ao de outros nomes de glycosides

que tem funcções identicas.

E - A agua destillada nos deu um extracto corado de vermelho e de sabor amargo quase imperceptivel. Pelo papel azul de tournesol verificamos nelle a existencia de acidos em dissolução. A uma parte do extracto defecado e tratado pelo carbonato de sodio, sendo em seguida filtrado, juntamos uma solução de perchlorureto de ferro, que fel-a precipitar em verde folha morta, caracteristico do tanino.

Addicionamos a uma outra porção do liquido obtido pelo processo acima algumas gottas de acido chlorhydrico e levamos á ebulição por alguns minutos e neutralisamos pela soda; o licor de Fehling foi redusido por esse liquido. Verificamos que essa reducção foi devida a traços de assucar consequente do desdobramento da dextrina, pela hydrolise com o acido, pois que no mesmo liquido haviamos previamente pesquisado glycose sem resultado positivo.

Para isolarmos a dextrina retomamos o extracto, evaporamol-o em uma capsula de platina até a consistencia de xarope, addicionamos-lhe tres volumes d'alcool absoluto, precipitando-se ella em flocos com ondulações abundantes. Dissolvida e saccharificada juntamos-lhe o licor de Fehling que deu logo a reacção caracteristica.

$\mathrm{O}$ extracto aquoso tratado pelo duplo de seu peso de alcool absoluto, previamente acidificado pelo acido acetico, e conservado em repouso durante 24 horas, precipitou mucilagem em flocos dispersos. A mucilagem não é precipitada de sua solução aquosa, como muitos outros principios identicos, pelo perchlorureto de ferro, entretanto o acetato de chumbo fal-a depositar-se em precipitado cascoso. A reacção de Lassaigne negativa, não denunciou a existencia de albuminoides soluveis nagua destillada.

F - A soda caustica diluida nos deu um extracto em 24 horas corado de vermelho escuro, insipido. Nelle pesquisamos materias albuminoides, phlobaphenos e acido metarabico. Feita a reacção de Lassaigne com o residuo da evaporação do extracto, depois de tratado pelo alcool, obtivemos em tubo fechado um belissimo precipitado azul Berlim, denunciador de substancias albuminoides soluveis na soda caustica diluida. Ainda no mesmo residuo reconhecemos a existencia de phlobaphenos e do acido metarabico.

$\mathrm{G}$ - Centrifugamos uma parte do extracto preparado com o acido chlorydrico diluido, a um porcento; depositadas por este meio as substancias em suspensão no liquido levamos uma pequena porção ao microscopio, tendo occasião de observar grãos esparsos de amido, uns com forma ovalar, outros com a forma de uma pera, de contornos irregulares e quase todos com hilo constituido pela convergencia de tres fendas figurando um Y.

A preparação submettida á acção da luz polarisada, deu-nos nitida a cruz de Malta, com o aspecto de duas finissimas raias escuras cruzados, sobre o fundo claro formado pelo grão de amido. Observamos no campo da preparação varios cristaes do systema cubico, 
caracteristicos do acido oxalico.

Filtrada uma outra porção do extracto, neutralisamol-a pelo ammoniaco e tratamol-a por duas vezes o seu volume d'alcool. Formou-se um deposito, que deixamos repousar durante algumas horas, com caracteres da parabina. Uma outra porção filtrada nos serviu para a dosagem das substancias soluveis no acido chlorydrico diluido, de modo que no peso do residuo não se acha incluido o do amido, que em suspensão no liquido ficou no filtro.

$\mathrm{H}$ - Ao peso do residuo que os dissolventes rejeitaram, representando o lenhoso, a cellulose e seus isomeros, reunimos o das perdas. Procuramos sempre evitar as perdas, conservando o mesmo filtro, o quanto nos foi possivel, na preparação dos differentes extractos.

I - Praticamos a determinação dos substancias mineraes fixas com 10 grammas de pó de cascas de catuaba, em capsula de platina tarada e em forno Dupré. Queimado o pó na temperatura do vermelho vivo e depois de collocada a capsula por algum tempo em desseccador de Schiff, foi ella de novo tarada encontrando-se o peso das cinzas por differença, na proporção acima mencionada.

As cinzas foram tratadas pela agua destillada, á quente, durante algumas horas; passada a solução em um filtro de Schleicher deixou neste um deposito. Lavado o filtro foi posto em uma capsula de platina para ser incinerado na chamma de um bico de Bunzen. Uma parte desse soluto obtido pela agua destillada, quente, serviu para a dosagem das substancias mineraes fixas soluveis n'agua, e na outra foram pesquisados e encontrados chloruretos.

Encontramos para 100 grammas de substancia 1,380 de saes soluveis nagua e 7,270 insoluveis, sendo estas ultimas dosadas por differença. Para a analyse qualitativa e quantitativa dos principios mais importantes das substancias mineraes fixas, retomamos outras 10 grammas de pó do vegetal. Depois de incinerado o pó, as cinzas foram dissolvidas em acido chlorydrico diluido á quente.

A solução evaporada até a seccura em capsula de platina, dissolvido novamente o residuo e filtrado, deixou um deposito de silica gelatinosa, que foi incinerado em capsula tarada. Feita a pesada obtivemos 0,220 de silica por cem partes de pó.

A solução chlorydrica foi neutralisada pelo ammoniaco e fervida para dosagem dos phosphatos, apparecendo um precipitado com os caracteres de alumina com traços de ferro. Filtrado o liquido ammoniacal foi tratado pela mistura magnesiana; mantido em temperaturas de $40^{\circ}$ por 24 horas, depositaram-se no fundo do vaso cristaes caracteristicos de phosphato ammoniaco magnesiano.

Decantado o líquido, o deposito crsitalino foi collocado em filtro de Schleicher e Schüll, lavado com agua ammoniacal e depois incinerado em capsula de platina: ficou um resíduo de pyrophosphato que devidamente transformado, por notação chimica, nos deu 1,gr.594 de anhydrido phosphorico, quantidade que demonstra a riqueza do vegetal em phosphoro.

A pesquisa do magnesio deu-nos ligeiros traços.

\section{COMPOSIÇÃO DAS CINZAS EM 100 GRAMMAS DE CORTICAL}

Saes soluveis nagua a quente............................. 1,380

Saes insoluveis........................................... 7,270

8,656

Silica.

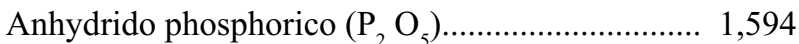

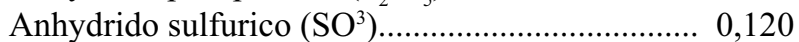

Cal............................................................. 3, 3,

Chloruretos de sodio e potassio.......................... 1,050

Acido carbonico................................................. 0,940

Magnesio (traços), peroxydo de ferro,

alumina, manganez (traços) ................................. 1,014

Substancias não verificadas e perdas $\quad \frac{-}{8,650}$

\section{BIBLIOGRAPHIA}

Almeida Pinto - Diccionario botanico.

André e José Rebouças - Ensaio de indice das madeiras do Brasil.

Antonio Gonçalves Dias - Diccionario da lingua tupi.

Baillon - Diccionaire botanique.

Barbosa Rodrigues - Hortus fluminense.

Behál-Chimie organique.

Bloxam - Chimie pratique.

Braulio Pereira - Leguminosas brasileiras - These de concurso.

Buignet - Manipilations de physique.

Caminhoá - Botanica geral e medica.

Caunet - Cours de botanique.

Crignon - Revue de chimie analytique - 1900.

Descourtilz - Florra pittoresca e medica das Antilhas.

Dragendorff - Analyse chimique des végétaux.

Estevam Raphael de Carvalho - Diccionario inedito da lingua tupi.

Ferdinand Hæffer - Historia da botanica.

Francisco da Luz Carrascosa - Jurubeba - These inaugural.

Frei Mariano - Flora fluminensis.

Freire Allemão, Custodio Alves Serrão, Ladisláo

Fresenius - Analyse quantitativa.

Gautier-Chimie organique.

H. Baillon - Le jardim botanique de la Faculté de Médecine de Paris.

Hillringhaus et Heilman - E'tude sur la yohimbine Spiegel.

João Joaquim da Silva Guimarães - Diccionario da lingua geral dos indios do Brasil.

Josephus Roddius - Plantarum brasiliensium nova genera. 
Manquat - Therapeutique.

Martius - Flora brasiliensis.

Martius - Glossaria linguarum brasiliensium.

Mello Moraes - Botanica brazileira.

Mello Oliveira - Enumeração scientifica de algumas plantas indigenas brasileiras.

Netto e Saldanha da Gama - Breve noticia sobre a collecção das madeiras do Brasil.

Nicoláo Moreira - Diccionario das plantas medicinaes indigenas brasileiras.

Nicoláo Moreira - Vocabulario das madeiras industriaes.

Pinson - De Indiae re naturalis et medica.

Pinson - Historia naturalis Brasiliae.

Pires de Almeida - Agriculture et les industries au

Brésil.

Pires de Almeida - Formulario officinal e magistral.

Rabuteau - Therapeutique.

Saget - Estudo botanico e chimico do Rumex crispus.

Saint-Hilaire - Flora Brasiliae meridionalis.

Santos Costa - Historia das plantas medicinaes portuguezas.

Silva Araujo - Noticia sobre o Elixir de catuaba e marapuama.

Teixeira de Souza - These de consurso - 1878 .

Van Tieghem - Elementos de botanica.

Visto,

Secretaria da Faculdade de Medicina da Bahia, 29 de Outubro de 1904.

O SECRETARIO

Dr. Menandro dos Reis Meirelles.

\section{Observação}

Esta espécie foi erroneamente identificada como Erytroxylum catuaba (Erytroxylaceae) pelo Dr. Arthur José da Silva em 1904. Tal equívoco foi verificado e apontado pelo botânico A. Ducke em 1966, o qual afirma tratar-se de fato de uma espécie de Trichilia, da família Meliaceae. Em 1996, Luis Carlos Marques conseguiu material fértil e identificou a catuaba da Bahia como Trichilia catigua Adr. Juss.- Meliaceae.

Tal erro botânico não desmerece o valor histórico e técnico do trabalho de A.J. da Silva, o qual buscou-se resgatar nesta oportunidade.

\section{REFERÊNCIAS}

Ducke A 1966. A catuaba na botânica sistemática, científica e pseudo-científica. Rev Bras Farm 47: 267-271.

Marques LC 1996. Contribuição ao esclarecimento da identidade botânica da droga vegetal catuaba. Revista Racine 8: 8-11.

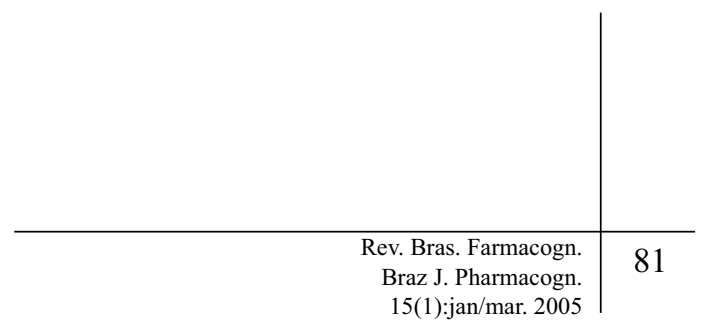

